\title{
Comparative Study of Forward and Backward Flow Forming Process using Finite Element Analysis
}

\author{
R.J. Bhatt and H.K. Raval
}

\begin{abstract}
Flow forming is a well known technique to produce cartridge case, rocket nose cones, rocket launcher casing etc. for defense industry. As the flow forming is the non linear plastic deformation process, it is required to understand the forces encountered and the strain distributions during the process for the efficient and successful product manufacturing. As it is a non linear plastic deformation process, still the force and strain distribution prediction is quite difficult. So that an attempt is made to predict the forces, stress, strain distributions in the present work, analysis has been carried out using ABAQUS/Explicit for forward and backward strategies. The work material has been taken as AA6063 due to its lighter weight, higher formability, ease of availability and versatile applications in aerospace and defense industry. The forces (axial, radial and circumferential) acting during the process have been obtained and reported along with the strain distribution in the length and thickness. It has been found that the axial and radial forces are higher in forward flow forming. The circumferential force is found higher in backward flow forming. Moreover plastic strain distribution along the thickness is found higher in forward flow forming and along length it is found higher in backward flow forming. The study will help to identify suitable strategy before actual production for different material and process conditions.
\end{abstract}

Keywords--- Flow Forming, Forward, Backward, Simulation, AA6063, ABAQUS, Forces, Stress, Strain

\section{INTRODUCTION}

$\mathrm{F}$ LOW forming is gradually used as metal forming process for production of axi symmetric engineering components in small or medium batch quantities. Flow forming is a locally plastic deformation applied to manufacture seamless tubes with thin walls and high precision dimensions. That facilitate customers to optimize design and reduce weight as well as cost, all of these are vital in automobile industries. This is mainly used for axi-symmetric and hard to deform material like $\mathrm{Cu}, \mathrm{Mg}$, Ti etc. alloys.

There basically two strategies have been applied in flow forming process i.e. forward and backward. In forward flow

R.J. Bhatt, Research Scholar, Mechanical Engineering Department, S V National Institute of Technology, Surat, Gujarat, India. E-mail: ravi_bhatt9988@yahoo.co.in

H.K. Raval, Professor, Mechanical Engineering Department, S V National Institute of Technology, Surat, Gujarat, India.E-mail:hkr@med.svnit.ac.in

DOI: 10.9756/BIJIEMS.8053 forming the deformation of tube takes place in the same direction of roller feed as shown in Fig. 1 (a) and in the backward flow forming the deformation takes place in the opposite direction of the roller feed as shown in Fig. 1 (b).

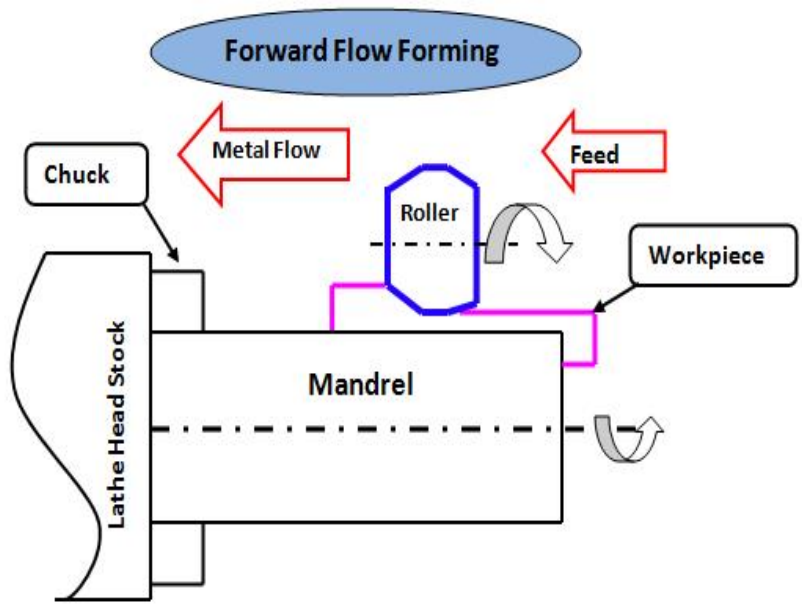

(a)

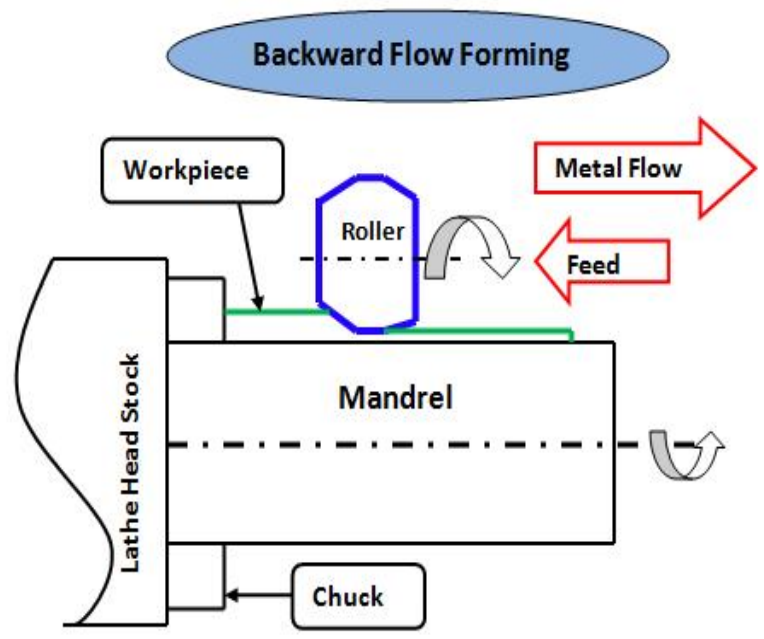

(b)

Figure 1: Schematic of Flow Forming Process

(a) Forward (b) Backward

Presently this flow forming technology is commercially used in aviation \& defense components manufacturing. The potential of this process has also been explored in other sectors too e.g. to produce thin walled tubes \& closed end cylinders for the chemical, nuclear, food, pharmaceutical, cryogenic, beverage, filtration and printing industries. The main advantage of the process are precise and accurate 
production with improved mechanical properties, effective material utilization, chip less production \& shorter processing time and elastic production process are some of the complimentary advantages of flow forming process [1].

There are a number of experimental and numerical studies on flow forming have been reported and still many opportunities are there to enhance the potential of this emerging technology. Zoghi et al. [2] did finite element analysis of hot tube necking process for $42 \mathrm{CrMo}$ steel. The working temperature was set as $850^{\circ} \mathrm{C}$. The study was concentrated for plastic strain and von-mises stresses and they were found that the equivalent plastic strain value is lower at the inner surface compared to top and middle surface. Also maximum value of stress generated in axial direction. These results were experimentally validated. In 2013, Zoghi et al. [3] also did simulation for 42CrMo to understand the deformation characteristics of hot tube necking process. They found that non uniform deformation takes place along the thickness layer due to non uniform contact between roller and blank in circumferential direction. Srinivasulu et al. [4] performed experiments on CNC flow-forming machine with a single roller for AA6082. From this study they observed that if the preform is annealed then the mechanical properties of flow formed tubes increases. Also the surface finish of the product is a function of roller radius, feed rate and mandrel speed. Molladavoudi et al. [5] used the NC lathe working on same principle of a flow forming machine for successful experimentation. Based on this experimental study researchers depicted that the Surface roughness, hardness \& diametral growth increases with increase in thickness reduction \& Geometrical accuracy decreases with increase in thickness reduction. Parsa et al. [6] used an explicit commercial finite element program to simulate the forward flow forming of tube. They established a correlation between feed rate and axial and angular velocities.

\section{MODELING AND SimUlation}

In this study ABAQUS/Explicit FE package has been used to analyze the process. Flow forming is influenced by many factors i.e. material properties, roller configuration (attack angle, relief angle, nose radius and size of roller), speed, feed, depth of forming, friction conditions etc. [1]. The forces (axial, radial and circumferential) acting during flow forming are given in Fig. 2. The success of the flow forming is mainly depending upon these forces. Here, AA6063 has been selected as work material based on the light weight, higher formability, ease of availability and versatile applications in aerospace and defense sectors. The chemical compositions and material properties of AA6063 are given in Table 1 and Table 2 respectively. The operating parameters have been taken based on the reported literature by Kim et al. [7]. Table 3 shows the operating conditions. The material and operating conditions kept same for both the strategies.

The rollers and mandrel are modeled by analytical rigid (undeformable) shell element. The analytical rigid does not requires the FE mesh as well the material property, leading to the reduction in the computational cost and the memory storage. For the deformable body (tube/blank), 8-nodes linear explicit reduced integration element C3D8R is used. In the contact region, finer mesh is adopted. Here, 6500 elements and 8400 nodes are used in the simulation. The smallest element size in the contact zone is $2.5 \times 1.25 \times 6.9 \mathrm{~mm}$ and the largest element size in the other part is $25 \times 1.25 \times 6.9 \mathrm{~mm}$. Finer mesh of $0.5 \mathrm{~mm}$ size have been adopted in the contact region. The initial meshed model for forward and backward flow forming is given in Fig. 3 and 4 respectively.

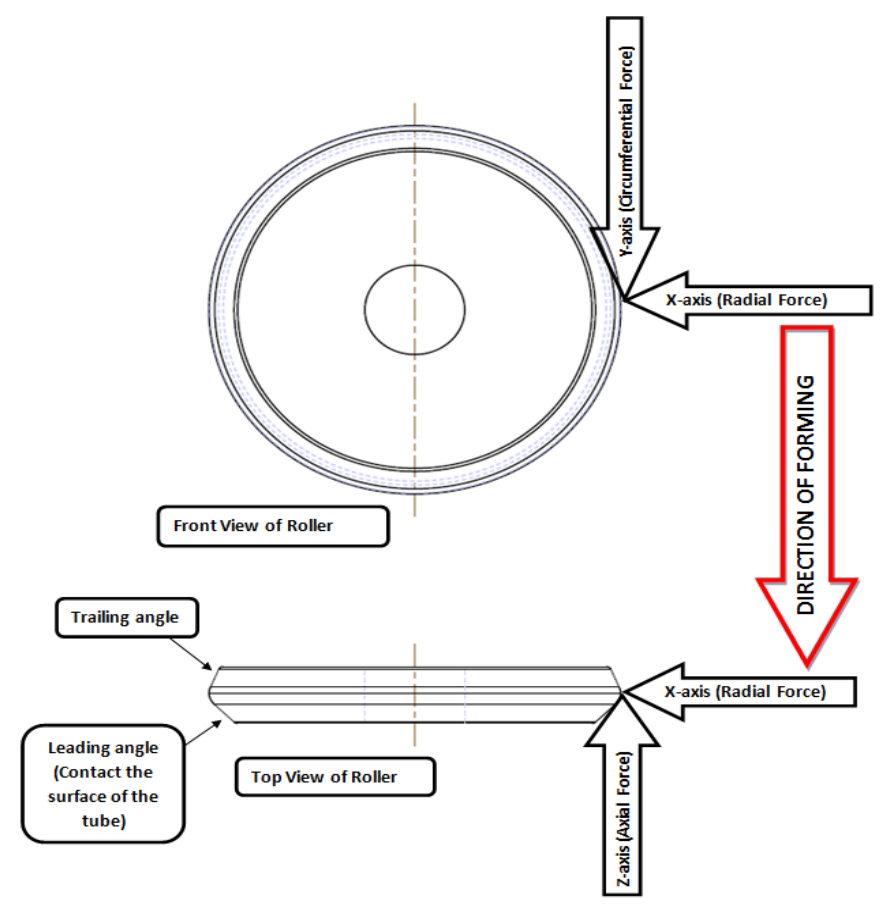

Figure 2: Forces acting during Flow Forming Process

Table 1: Chemical Composition of AA6063 (\%)

\begin{tabular}{|l|l|l|l|l|l|l|}
\hline Element & $\mathrm{Cu}$ & $\mathrm{Zn}$ & $\mathrm{Si}$ & $\mathrm{Mn}$ & $\mathrm{Mg}$ & $\mathrm{Fe}$ \\
\hline AA6063 & 0.069 & 0.1 & 0.34 & 0.013 & 0.42 & 0.1 \\
\hline
\end{tabular}

Table 2: Mechanical Properties of AA6063 [7]

\begin{tabular}{|l|l|}
\hline Density & $2700(\mathrm{Kg} / \mathrm{m} 3)$ \\
\hline Elastic Modulas & $68.9(\mathrm{GPa})$ \\
\hline Yield Strength & $48.3(\mathrm{MPa})$ \\
\hline Ultimate Strength & $89.6(\mathrm{MPa})$ \\
\hline Poisson's Ratio & 0.33 \\
\hline
\end{tabular}

Table 3: Operating Parameters [7]

\begin{tabular}{|l|l|l|l|}
\hline Blank & $\begin{array}{l}\text { Outer Diameter } \\
(\mathrm{mm})\end{array}$ & $\begin{array}{l}\text { Initial Length } \\
(\mathrm{mm})\end{array}$ & $\begin{array}{l}\text { Initial Thickness } \\
(\mathrm{mm})\end{array}$ \\
\hline 35 & 40 & 50 & 2.5 \\
\hline Roller & Attack Angle & Relief Angle \\
\hline $\begin{array}{l}\text { Outer Diameter } \\
(\mathrm{mm})\end{array}$ & $5^{\circ}$ \\
\hline 54 & $25^{\circ}$ & 30 \\
\hline Spinning Parameters & 0.1 \\
\hline Spindle Speed (RPM) & 40 \\
\hline Feed Rate (mm/rev) & \\
\hline Reduction Ratios (\%) & \\
\hline
\end{tabular}

Initial and boundary conditions have been applied based on the roller linear and angular velocity. Here the inertia of the roller has been considered and mass scaling factor 100 is applied to reduce simulation time. The frictional contact between the workpiece and the mandrel and between the 
workpiece and the roller is assumed to follow the Coulomb law with the friction coefficient of 0.1 and 0.001 respectively. This friction model assumes that the relative sliding occurs between two contact surfaces when the equivalent shear stress reaches to the critical values at the friction surfaces. Simulation time is considered as 30 seconds.

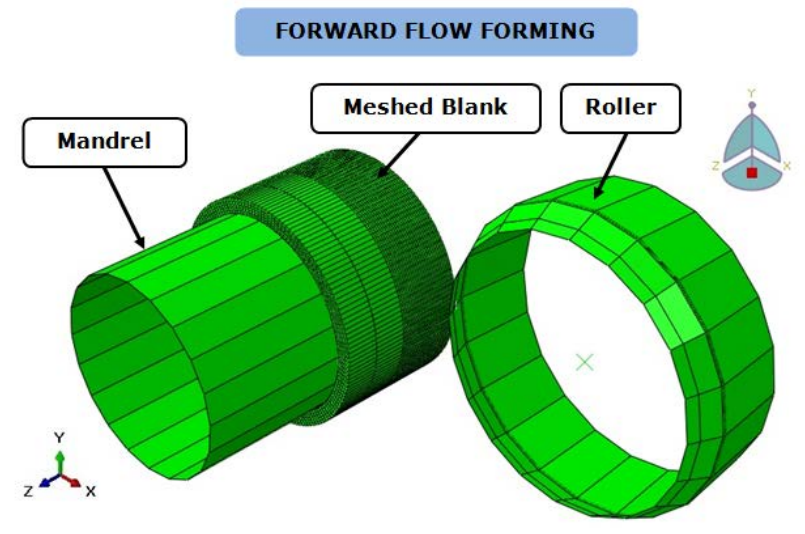

(a)

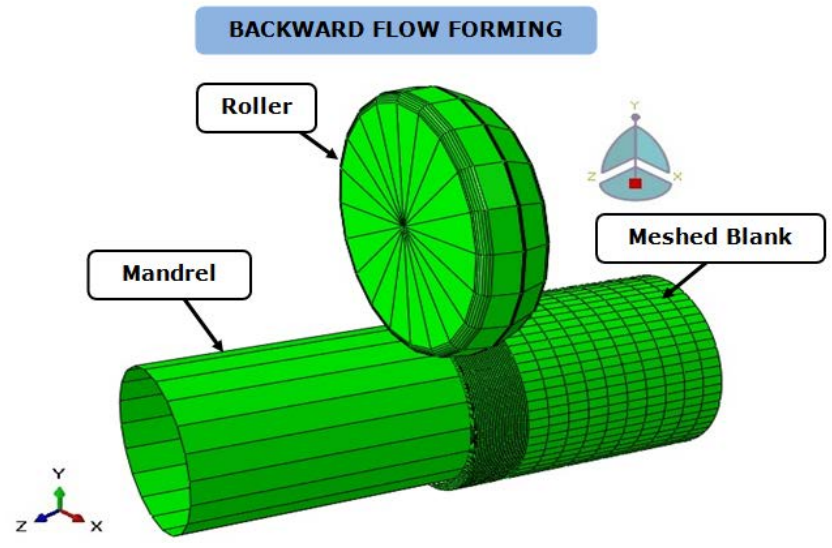

(b)

Figure 3: Initial Meshed Model (a) Forward (b) Backward

\section{RESULTS AND DISCUSSION}

By using the ABAQUS/Explicit the analysis has been carried out for forward and backward flow forming process using single roller and single pass. The acting forces have been obtained. Axial force, radial and circumferential force comparisons are shown in Fig. 4, 5 and Fig. 6 respectively.

Axial force is found maximum for both the strategies compared to radial and circumferential forces due to the compression and shear deformation in axial direction as shown in Fig. 4. The value of axial force is $2500 \mathrm{~N}$ and 1800 $\mathrm{N}$ for forward and backward strategy respectively. Figure 5 represents the radial force comparison and it is found as the second predominant force during the flow forming process. The value for radial force is higher in forward process (max. $1000 \mathrm{~N}$ ) compared to backward (max. $800 \mathrm{~N}$ ). The circumferential force is found much higher in backward process (max. $650 \mathrm{~N}$ ) compared to forward (max. $50 \mathrm{~N}$ ) due to the opposite flow of material against the roller feed.

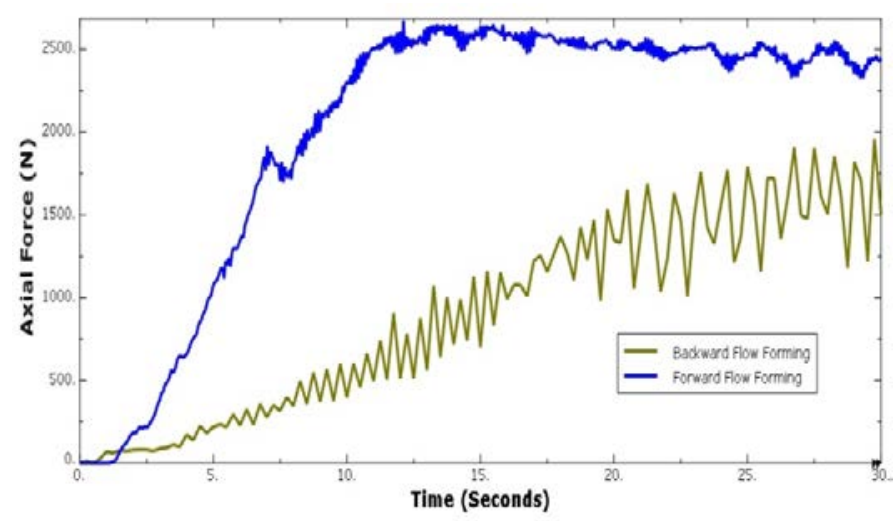

Figure 4: Axial Force during Forward and Backward Flow Forming

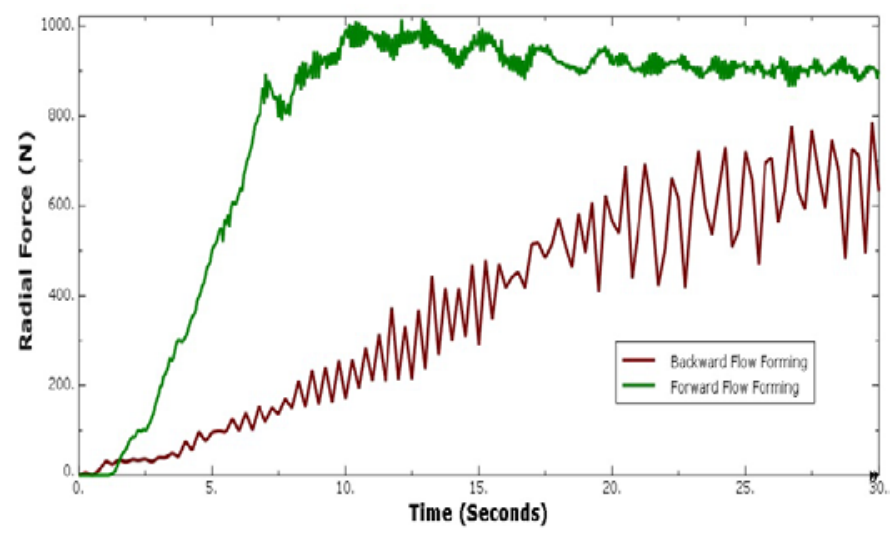

Figure 5: Radial Force during Forward and Backward Flow Forming

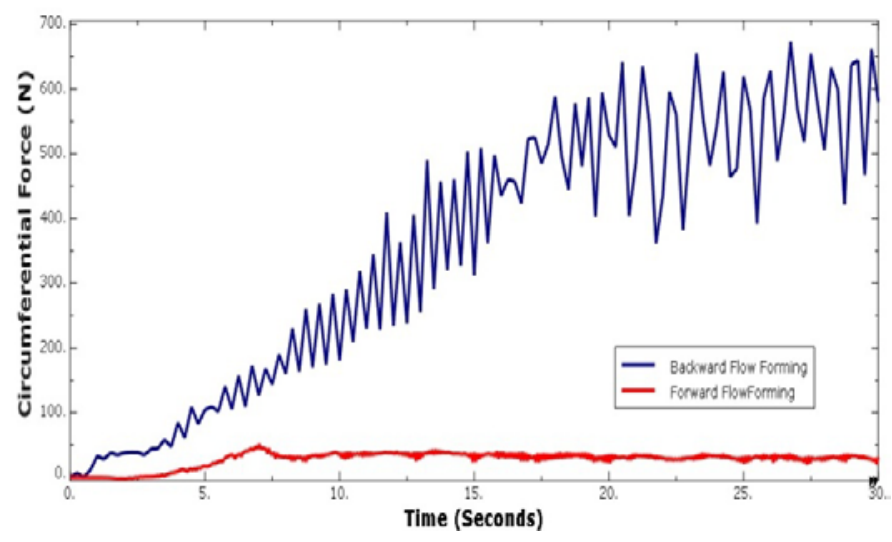

Figure 6: Circumferential Force during Forward and Backward Flow Forming

The von mises stresses generated due to forces and equivalent plastic strain for both the strategies have been obtained and reported. The value of max. von mises stress is found to be 162.0 MPa (Fig. 7) for forward process and 196.5 MPa (Fig. 8) for backward process. Also the max. value of equivalent plastic strain is found as 1.622 (Fig. 9) and 2.264 (Fig. 10) for forward and backward process respectively. It has been noted that the higher strain as well as deformation can be achieved during backward process resulting in higher stresses compared to forward process. 


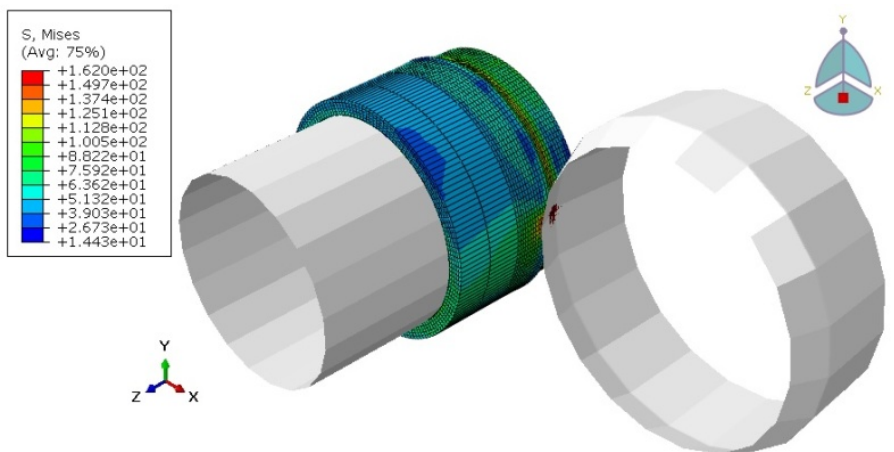

Figure 7: Von-mises Stresses for Forward Flow Forming Process

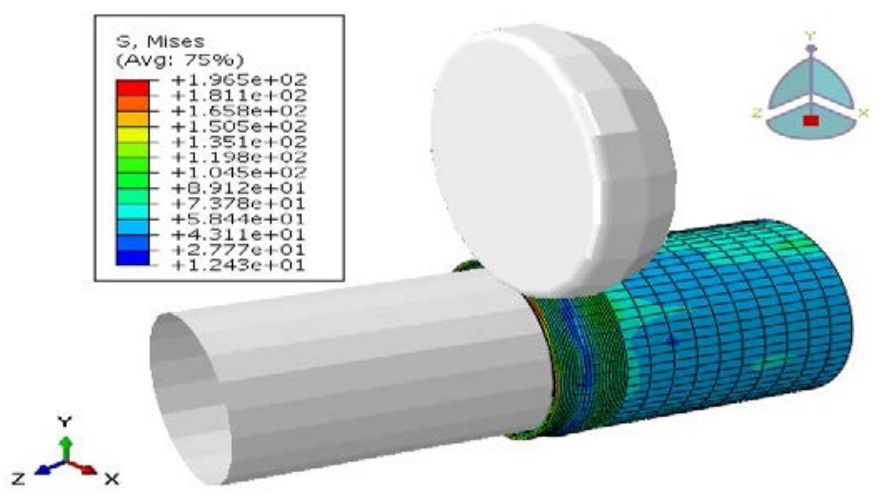

Figure 8: Von-mises Stresses for Backward Flow Forming Process

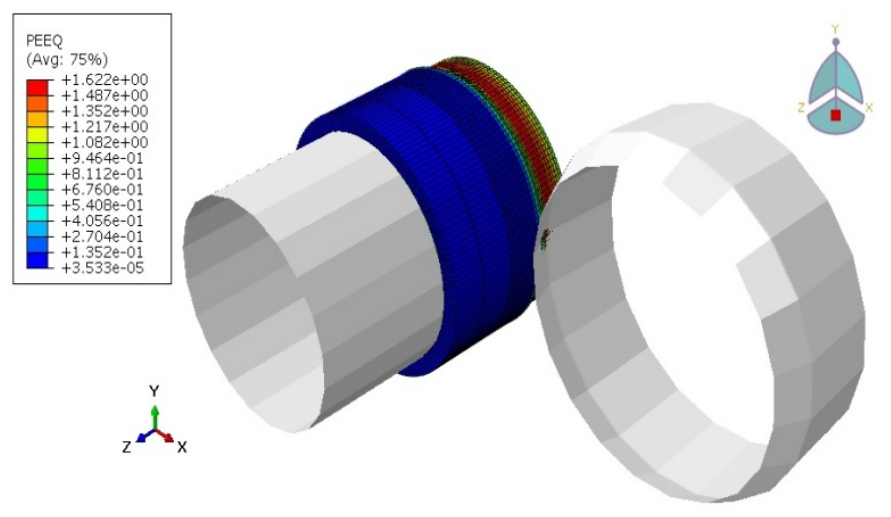

Figure 9: Equivalent Plastic Strain for Forward Flow Forming Process

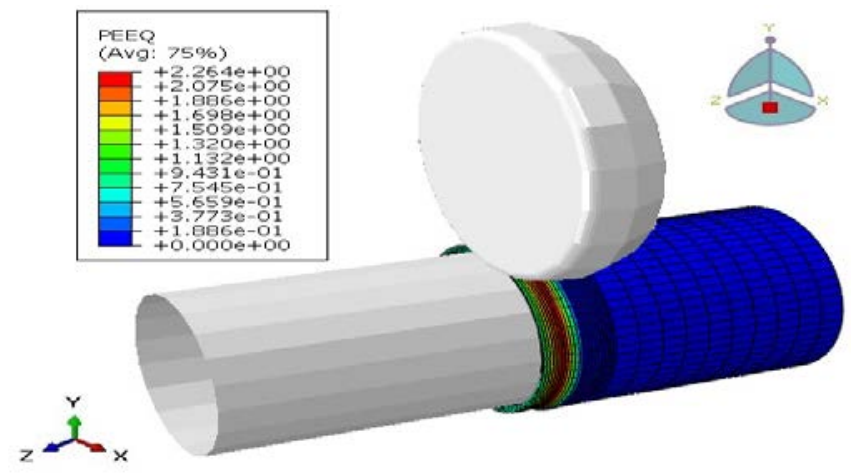

Figure 10: Equivalent Plastic Strain for Backward Flow Forming Process
Moreover, the thickness distribution has also been obtained in thickness and length directions of the tube. In the thickness directions three layers have been defined and corresponding plastic strain have been obtained. The selection of elements is shown in Fig. 11 in order to obtain thickness plastic strain. As shown in Fig. 12 that the top layer of tube experienced severe deformation compared to middle and bottom layer. The reason behind that is the roller is in contact with top layer and it gets deformed first. The middle surface follows the deformation to top surface. Bottom layer surface is constrained with higher friction with mandrel so that it experiences very little deformation in thickness direction.

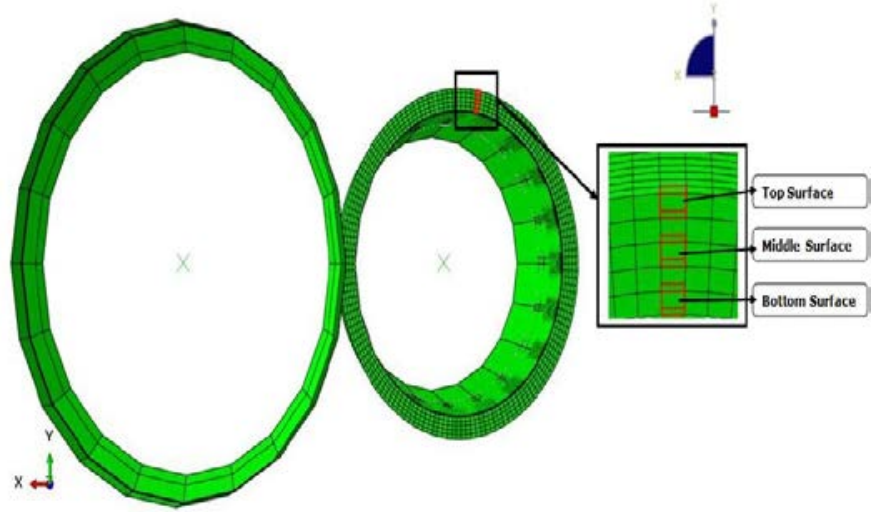

Figure 11: Selection of Elements in Thickness Direction

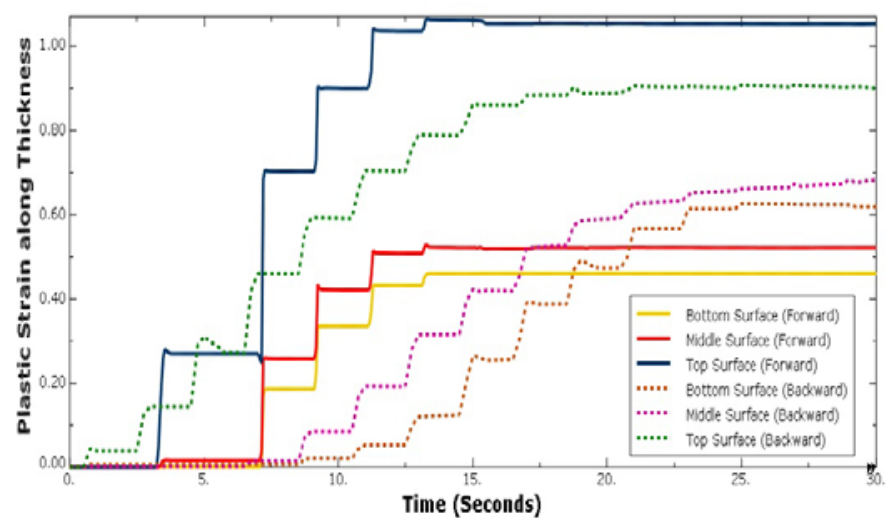

Figure 12: Thickness Strain Distribution along with Time

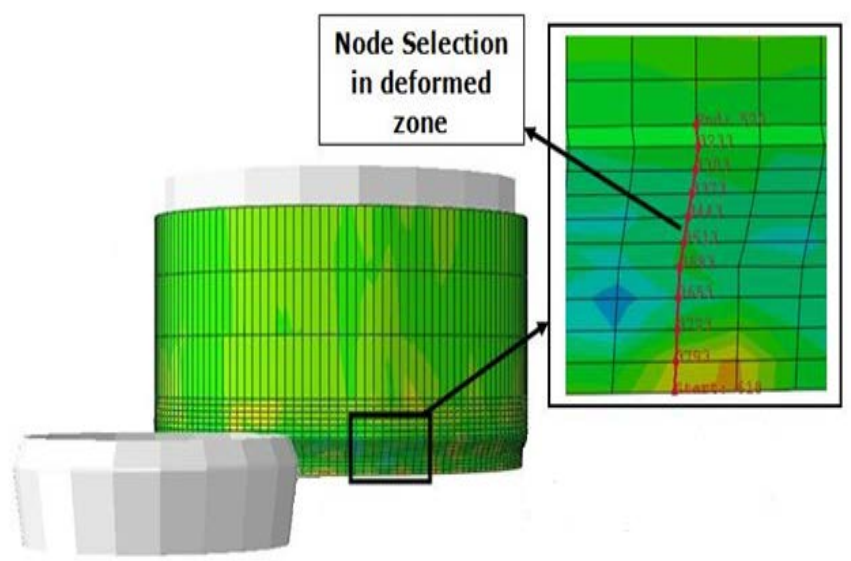

Figure 13: Node Selection in Deformed Zone to Determine Length Strain 
It can be seen from Fig. 12 that the thickness strain is achieved higher during forward process compared to backward.

The length strain is obtained by selection of nodes in the deformed region as shown in Fig. 13. It has been observed that the length direction plastic strain/deformation is achieved higher in backward process (approx. 2.1) compared to forward process (approx. 1.5) as per Fig. 14. It can be noted that to obtain the higher thickness distribution forward process is favorable and backward process is found more suitable to achieve higher length strain.

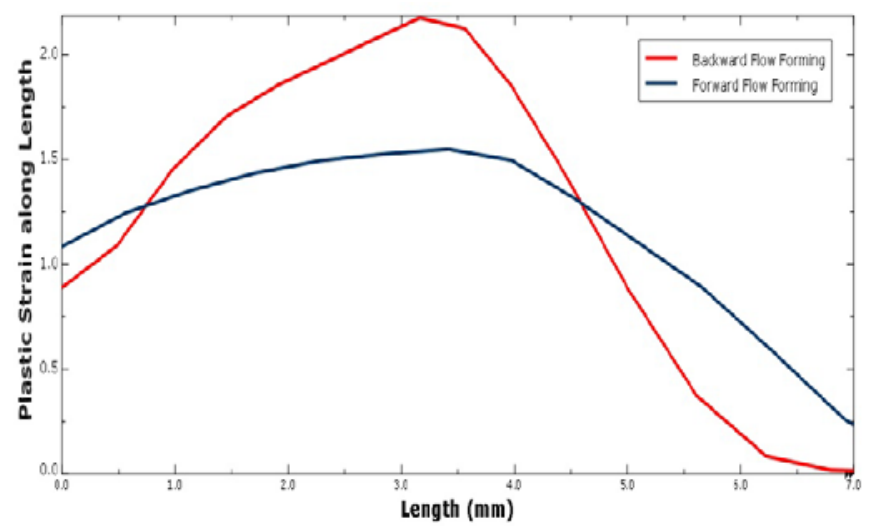

Figure 14: Length Strain Distribution along with Time

\section{CONCLUSION}

From present study following broad conclusions can be drawn.

- Axial force is found to be much higher for both the strategies compared to radial and circumferential force.

- Radial force is second prominent during the flow forming process for both strategies. Circumferential force is found to be higher in backward process due to the deformation of the tube against the roller feed.

- The von mises stresses for both the strategies are having minor difference. The equivalent plastic strain is found to be higher in backward process.

- The higher value of thickness strain can be obtained through forward process whereas higher value of length strain can be obtained through backward process.

\section{REFERENCE}

[1] B. Avitzur, “Handbook of Metal Forming Process” John Wiley and Sons, Inc., Canada, Pp. 73-148, 1983

[2] H. Zoghi, A. F. Arezoodar, "Finite element study of stress and strain state during hot tube necking process", Journal of Engineering Manufacturing, vol. 227 (4), Pp. 551-564, 2014

[3] H. Zoghi, A. F. Arezoodar, M. Sayeaftabi, "Enhanced finite element analysis of material deformation and strain distribution in spinning of 42CrMo steel tubes at elevated temperature”, Journal of Materials and Design, vol. 47, Pp. 234-242, 2013

[4] M. Srinivasulu, M. Komaraiah, C.S. Krishna Prasada Rao, "Experimental studies on the characteristics of AA6082 flow formed tubes”, Journal of Mechanical Engineering and Research, vol. 4, Pp. 192-198, 2012

[5] H.R. Molladavoudi, F. Djavanroodi, "Experimental study of thickness reduction effects on mechanical properties and spinning accuracy of aluminum 7075-O, during flow forming”, International Journal of Advanced Manufacturing Technology, vol. 11, Pp. 949-957, 2011

[6] M. H. Parsa, A. M. A. Pazooki, A. M. Nili, "Flow forming and flow formability simulation", International Journal of Advanced Manufacturing Technology, Pp. 463-473, 2009

[7] N. Kim, H. Kim, K. Jin, "Minimizing the Axial Force and material build-up in the tube flow forming process", International Journal of Precision Engineering and Manufacturing, vol. 14 (2), Pp. 259-266, 2013

[8] R. J. Bhatt, H. K. Raval, "Experimental Study on Backward Flow Forming Process", Proceedings of Recent Advances in Manufacturing (RAM-2015), Pp.114-120, 2015

[9] S. Kalpakcioglu, "On the Mechanics of Shear Spinning", Trans ASME, pp. 125-130, 1961

[10] R. J. Bhatt, H. K. Raval, "Process Variables of Tube Flow Forming Process: A Review", Proceedings of Advances in Materials and Product Design (AMPD-2015), Pp.114-120, 2015 